\title{
A STUDY OF RHEUMATISM IN A GROUP OF SOLDIERS WITH REFERENCE TO THE INCIDENCE OF TRIGGER POINTS AND FIBROSITIC NODULES
}

\author{
BY
}

\author{
L. G. C. E. PUGH and T. A. CHRISTIE
}

The nature and significance of the trigger points and nodules characteristically present in patients suffering from acute attacks of fibrositis has been discussed in recent papers by Copeman and Elliott. Elliott, using the myoscillagraph, has shown that areas of localized tenderness on deep palpation may be due to subclinical spasm in portions of the underlying muscle, and suggests various ways in which this state of spasm may arise. Copeman on the other hand believes that the tender nodules and trigger points are the clinical signs of changes in fibro-fatty tissues involving oedema and in some cases herniation of discrete lobules of fat.

We have approached the subject from a different angle by examining a group of healthy soldiers for the presence of nodules, tender or otherwise, and of trigger points. We also obtained from each individual information as to whether he had at any time in his life suffered from pains in the joints, pain and stiffness of the back, or other symptoms of the rheumatic group of diseases. After excluding histories readily explained on non-rheumatic grounds, the results were compared with the incidence and distribution of trigger points and nodules which had been found. Owing to the lack of precision of a diagnosis founded on past history, it seemed wiser to choose a generic term of description for the positive cases rather than seek to distinguish between different types; and we have, therefore, employed the term "rheumatism," and have referred to individuals giving positive histories as " rheumatic subjects."

Five hundred and twenty-two members of a territorial regiment, R.A. were examined in Holland in the spring of 1945 . The majority had served with the unit since the outbreak of war, for which reason their ages showed a somewhat unusual distribution for a forward unit having a range of 19 to 42 , with modes of 25 and 33 years. The men had been living in tents on low-lying water-logged ground in the Rhine delta. They had been in action continuously all the winter. In spite of the cold and damp living conditions and the strain of battle, the health of the troops had been good. We were particularly impressed by the low sick rate due to rheumatism and attributed this to the quality of the personnel and their high morale. The fact that the men were thoroughly conditioned to exposure was probably also an important factor contributing to the low incidence of rheumatic disability.

\section{Method}

The back, shoulders, and buttocks of each individual was examined for the presence of trigger points and palpable nodules. A trigger point is defined as a circumscribed area of tenderness, firm palpation of which causes pain and reflex contraction of the adjacent or underlying muscles. Upon the conclusion of this examination the rheumatic history was taken. The following symptoms, unless adequately explained by anticedent trauma, postura defects, unaccustomed exertion, or an incipient febrile illness, were accepted as falling within the rheumatic category: stiffness and pain of muscles and joints during movement; pain and weakness on violent movement; occasional and transitory stabbing pain on initiating movements; periodic aching pain referred to joints or muscles and present during rest.

\section{Results}

The results of this investigation are set out in Tables I and II.

TABLE I.-SHOWING RELATIONSHIP BETWEEN THE RHEUMATIC DISPOSITION AND THE PRESENCE OF TRIGGER POINTS

\begin{tabular}{|c|c|c|c|}
\hline & \multicolumn{2}{|c|}{ Number of Individuals } & \multirow{2}{*}{ Total } \\
\hline & $\begin{array}{l}\text { Trigger } \\
\text { points } \\
\text { present }\end{array}$ & $\begin{array}{l}\text { Trigger } \\
\text { points } \\
\text { absent }\end{array}$ & \\
\hline $\begin{array}{l}\text { Rheumatic subjects . } \\
\text { Non-rheumatic sub- }\end{array}$ & & & 143 \\
\hline \begin{tabular}{lll} 
jects & \multicolumn{1}{c}{ Total } & $\ldots$
\end{tabular} & $\begin{array}{ll}11 & (3 \%) \\
57(11 \%)\end{array}$ & $\begin{array}{l}368(97 \%) \\
465(87 \%)\end{array}$ & $\begin{array}{l}379 \\
522\end{array}$ \\
\hline
\end{tabular}

Note.-Five cases of rheumatic fever in adolescence without subsequent symptoms, and one case of rheumatic fever in January, 1945, are included in Table I but omitted from Table II. 
TABLE II.-CLASSIFICATION OF RHEUMATIC CASES ACCORDING TO PART OF BODY PRINCIPALLY AFFECTED, AND FREQUENCY OF TRIGGER POINTS IN EACH GROUP

\begin{tabular}{|c|c|c|c|}
\hline & $\begin{array}{l}\text { Trigger } \\
\text { points } \\
\text { present }\end{array}$ & $\begin{array}{l}\text { Trigger } \\
\text { points } \\
\text { absent }\end{array}$ & Total \\
\hline 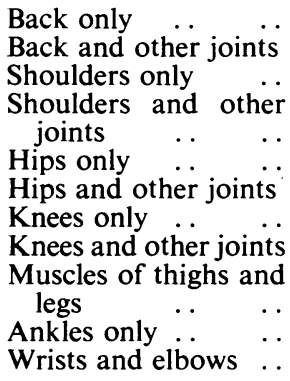 & $\begin{array}{r}25 \\
4 \\
9 \\
2 \\
1 \\
1 \\
2 \\
- \\
1\end{array}$ & $\begin{array}{r}29 \\
3 \\
31 \\
\\
5 \\
6 \\
2 \\
4 \\
4 \\
\\
6 \\
1 \\
1\end{array}$ & 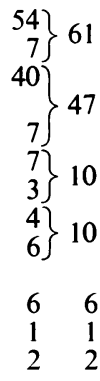 \\
\hline Total & 45 & 92 & 137 \\
\hline
\end{tabular}

\section{Rheumatic History}

In 143 out of 522 individuals $(28 \%)$ a positive history of rheumatic symptoms was obtained. In the majority of cases these symptoms were of a minor and transient character, not requiring treatment. They were associated particularly with changes of weather, periods of cold and damp, the wearing of wet clothes, or sleeping between damp blankets. Of those more severely affected not all had reported sick; and there were some who in spite of chronic pain and stiffness carried on with their work for fear of having to leave the unit. Ninety-three out of 143 subjects attributed their symptoms directly to climatic influences, and only 10 had been free of symptoms during the previous winter. At the time of this investigation the weather had been warm and dry for the past three weeks and there were only six then complaining of rheumatic pain.

The classification of cases given in Table II shows that the back or upper part of the body was affected predominantly, in greater frequency than the lower limb; the proportions being: back $45 \%$, shoulders and upper limb $35 \%$, lower limb $20 \%$. From previous experience, it is considered probable that this distribution is related to the nature of the work in a heavy artillery regiment, involving as it does strenuous lifting, heaving, and pushing, and that a similar investigation carried out on an infantry unit would reveal a relatively higher incidence of involvement of the lower extremity.

Of 14 men who had suffered from rheumatic fever in adolescence, 9 complained of occasional pain and stiffness in the joints brought on by exposure, and affecting principally the knees and shoulders (in 2 cases the back also); the other 5 had remained free of symptoms since the original attack. One individual was encountered who had his first attack of rheumatic fever three months previously at the age of 28 years.

\section{Nodules}

Palpable nodules were found to be present in $16 \%$ of rheumatic and $15 \%$ of non-rheumatic individuals; hence it is concluded that as far as rheumatism is concerned their presence is of no significance. They occurred with equal frequency in the region below the iliac crests and along the borders of the scapulae, but were not found in the lumbar region of the back, a common site for trigger points. When nodules were discovered in rheumatic subjects, in half the cases one or more of them was tender, and the tender ones were always located in the iliac region. The finding of tender nodules below the iliac crests has led Elliott (1944) to suggest that the quality of tenderness in nodules depends merely on their situation in an area where on palpation they are compressed against bone or ligament. In the present investigation, however, tender as opposed to non-tender nodules were present four times as often in rheumatic as in non-rheumatic subjects. The quality of tenderness therefore appears definitely to be associated with a history of rheumatic pain.

\section{Trigger Points}

Trigger points were found in $30 \%$ of rheumatic and $3 \%$ of apparently non-rheumatic subjects. The association of trigger points with a history of rheumatic symptoms is therefore a strong one. Tender nodules are included in this result since it appears to be the quality of tenderness that is significant and not palpability. They therefore come within the definition of trigger points and are included under that heading in Tables I and II. The situations in which trigger points were located were as follows: the lateral borders of the paravertebral muscles; the sacral region; below the iliac crests; medial to the vertebral border of the scapula; the upper border of the trapezius muscle; in the supra-scapular region. It may be noted that most of these situations conform to the areas of the basic fat pads defined by Copeman (1944) as being sites in which trigger points are most commonly to be found in the acute stage of attacks of fibrositis.

In the rheumatic subjects trigger points were situated in regions previously affected by symptoms: e.g. along the lateral borders of the paravertebral muscles in the cases of lumbago; or in areas from which pain commonly radiates in the acute stage, e.g. the upper border of trapezius or the scapula region in the case of fibrositis of the upper part of the back and shoulders. Out of 45 subjects there were only 3 in whom the site of the trigger points was unrelated to the region affected by the rheumatic symptoms.

\section{Discussion}

The symptoms described by most of the rheumatic subjects were characteristic of fibrositis. In view of the high incidence in a fit body of men of high morale and the close relationship to climatic factors, it appears to us unlikely that such symptoms 
can be regarded as entirely psychogenic. On the other hand, since men of low morale and unstable personality tend to exaggerate and prolong their minor disabilities, there is no doubt that among rheumatic subjects reporting sick and receiving medical treatment a high proportion show neurotic traits. So common is this finding that several authorities, in the absence of unequivocal pathological information, have been led to doubt the existence of a physical basis for fibrositis.

Similarly, the persistence of trigger points in the absence of symptoms in $30 \%$ of rheumatic compared with $3 \%$ of non-rheumatic subjects might be explained in terms of " function," both symptoms and trigger points being interpreted as signifying a low threshold for sensations of pain. But since the trigger points, though conforming to a general pattern, were seldom symmetrical in distribution and often occurred singly, we submit that they are more readily interpreted as evidence of some persisting structural or biochemical change in the tissues, the nature of which will eventually be determined. Copeman $(1944,1945)$ has adduced evidence that trigger points are the result of pathological changes in fibro-fatty tissues, and not in muscle or fibrous tissue. Elliott (1944), on the other hand, has recently suggested that in some cases of rheumatic pain, trigger points are due to circumscribed areas of muscle spasm. The results of the present investigation lend support to the former view, for it is difficult to accept the possibility of muscle spasm persisting in the absence of symptoms. In the acute stage of an attack of fibrositis, on the other hand, muscle spasm may well arise as a result of reflex irritation from the specific lesions in neighbouring tissues. Such a mechanism has clearly been demonstrated in the case of sciatica due to prolapse of an intervertebral disc, and is held to be responsible in part for the pain in this condition. Similarly in fibrositis, the symptoms may have their origin partly in the fibrositic lesion, and partly in the associated muscle spasm.

\section{Summary}

1. Of 512 fit soldiers, $146(28 \%)$ gave a previous history of pain and stiffness of muscles and joints, considered to be of rheumatic origin.

2. Of these 146 rheumatic subjects, trigger points or tender nodules were found to be present on palpation in $46(32 \%)$, although only 6 had symptoms at the time of examination.

3. Among 379 apparently non-rheumatic subjects, tender nodules or trigger points were found in only $11(3 \%)$.

4. Non-tender nodules were found in equal proportions of rheumatic and non-rheumatic subjects, and are therefore considered to have no rheumatic significance.

5. The significance of these results is discussed.

In conclusion we wish to express our gratitude to Lt.-Col. Burrows, R.A., for granting permission for this work to be carried out, and to Lt.-Col. W. S. C. Copeman, R.A.M.C., for his advice and encouragement in the preparation of this paper.

\section{REFERENCES}

Copeman, W. S. C. and Ackerman, W. L. (1944), Quart. J. Med.

Elliott, F. A. (1944). Ann. rheum. Dis., 4, 22. 